\title{
Biological and Structural Characterization of Crotoxin and New Isoform of Crotoxin B PLA2 (F6a) from Crotalus durissus collilineatus Snake Venom
}

\author{
Luis Alberto Ponce-Soto, ${ }^{1,4}$ Bruno Lomonte, ${ }^{3}$ Lea Rodrigues-Simioni, ${ }^{2}$ José Camillo Novello, ${ }^{1}$ \\ and Sergio Marangoni ${ }^{1}$
}

\begin{abstract}
A new crotoxin B isoform $\mathrm{PLA}_{2}$ (F6a), from Crotalus durissus collilineatus was purified from by one step reverse phase HPLC chromatography using $\mu$-Bondapack C-18 column analytic. The new crotoxin $\mathrm{B}$ isoform $\mathrm{PLA}_{2}$ (F6a), complex crotoxin, the catalytic subunit crotoxin B isoform $\mathrm{PLA}_{2}(\mathrm{~F} 6 \mathrm{a})$ and two crotapotin isoforms (F3 and F4), were isolated from the venom of Crotalus durissus collilineatus. The crotapotins isoforms F3 and F4 had similar chemical properties, the two proteins different in their ability to inhibit of isoforms of $\mathrm{PLA}_{2}$ (F6 and F6a). The molecular masses estimated by MALDI-TOF mass spectrometry were: crotoxin B: 14,943.14 Da, crotapotin F3: 8,693.24 Da, and crotapotin F4: 9314.56 Da. The new crotoxin $\mathrm{B}$ isoform $\mathrm{PLA}_{2}$ (F6a) contained 122 amino acid residues and a $\mathrm{pI}$ of 8.58. Its amino acid sequence presents high identity with those of other $\mathrm{PLA}_{2} \mathrm{~s}$, particularly in the calcium binding loop and active site helix 3 . It also presents similarities in the $\mathrm{C}$-terminal region with other myotoxic $\mathrm{PLA}_{2} \mathrm{~s}$. The new crotoxin B isoform $\mathrm{PLA}_{2}$ (F6a) contained 122 amino acid residues, with a primary structure of HLLQFNKMIK FETRRNAIPP YAFYGCYCGW GGRGRPKDAT DRCCFVHDCC YGKLAKCNTK WDFYRYSLKS GYITCGKGTW CEEQICECDR VAAECLRRSL STYRYGYMIY PDSRCRGPSE TC. A neuromuscular blocking activity was induced by crotoxin and new crotoxin B isoform PLA 2 (F6a) in the isolated mouse phrenic nerve diaphragm and the biventer cervicis chick nerve-muscle preparation. Whole crotoxin was devoid of cytolytic activity upon myoblasts and myotubes in vitro, whereas new crotoxin $\mathrm{B}$ isoform $\mathrm{PLA}_{2}$ (F6a) was clearly cytotoxic to these cells.
\end{abstract}

KEY WORDS: Biventer cervicis chick; Crotalus durissus collilineatus; crotoxin; crotoxin B isoform PLA 2 (F6a); mass spectrometry Maldi-Tof; myoblasts; myotubes; venom; neurotoxin.

\section{INTRODUCTION}

In Brazil, bites by subspecies of the rattlesnake Crotalus durissus are responsible for $7-8 \%$ of the bites

\footnotetext{
${ }^{1}$ Departamento de Bioquímica, Instituto de Biologia (IB), Universidade Estadual de Campinas (UNICAMP), CP 6109, CEP 13083-970, Campinas, SP, Brazil.

${ }^{2}$ Departamento de Farmacologia, Faculdade de Ciências Médicas, Universidade Estadual de Campinas (UNICAMP), Campinas, SP, Brazil.

${ }^{3}$ Facultad de Microbiología, Instituto Clodomiro Picado, Universidad de Costa Rica, San José, Costa Rica.

${ }^{4}$ To whom correspondence should be addressed. e-mail: poncesoto@ yahoo.com.ar
}

by venomous snakes reported annually in this country (Araújo, 2003). Envenoming by these snakes is characterized by neurotoxicity, systemic myotoxicity,

\footnotetext{
Abbreviations: Crotoxin B, complex crotoxinB; HPLC-FR, High performance liquid chromatograph reverse phase; F3 and F4, crotapotins isoforms; F6 and F6a, isoforms of PLA 2 ; Maldi-Tof, Matrix Assisted Laser Desorption Ionization-Time-of-flight. Mass Spectrometry; $\mu$-Bondapack C-18, column HPLC with 18 carbons; PTC-aminoacids, phenylthiocarbamyl- aminoacids; EDTA, ethylenediaminetetraacetic; DTT, dithiothreitol; RC-PLA 2 , reduced and carboxymethylated-PLA 2 ; SV8, Staphylococcus aureus protease; TFA, trifluoroacetate; Cvx, convulxin; Gyr, gyroxin; MS spectral profiles, mass spectrometric spectral profiles.
} 
edema and acute renal failure (Azevedo-Marques, 1982).

Crotoxin is a potent neurotoxic and myotoxic heterodimeric phospholipase $\mathrm{A}_{2}\left(\mathrm{PLA}_{2}\right)$ present in high concentration in the venom of various South American subspecies of the rattlesnake Crotalus $d u$ rissus (Lennon and Kaiser, 1990; Beghini, 2000; Ponce-Soto, 2002; Rangel-Santos, 2004). Crotoxin exists in several isoforms, which vary in their biological activity, probably as a result of the heterogeneity in the $\mathrm{PLA}_{2}$ and crotapotins (Faure and Bon, 1987). The multiplicity and diversity of crotoxin isoforms may be due to post-translational modification of a unique precursor of crotoxin or from the expression of different mRNAs (Faure and Bon, 1987, 1988; Faure, 1991, 1993, 1994; Oliveira, 2002).

Snake venom $\mathrm{PLA}_{2} \mathrm{~S}$ displays a variety of activities, such as neurotoxicity, myotoxicity, cardiotoxicity and hemolysis that may be modulated by specific receptors located on target cells (Kini and Evans, 1989; Gutiérrez and Ownby, 2003; Kini, 2003). Indeed, $\mathrm{PLA}_{2}$ receptors classified as types $\mathrm{M}$ and $\mathrm{N}$ (Lambeau and Lazdunski, 1999) have been identified in various types of cells. Snake venom $\mathrm{PLA}_{2}$ can bind to $\mathrm{M}$ receptors, which are the most common type found in human macrophages and muscle cells, and these may mediate some of the deleterious actions of venom $\mathrm{PLA}_{2} \mathrm{~S}$, although this remains to be conclusively demonstrated (Gutiérrez and Ownby, 2003).

Crotalus durissus collilineatus is a clinically important rattlesnake species found in central Brazil, but there have been few studies of its venom and its main toxin a crotoxin homolog. The absence of crotamine in Crotalus durissus collilineatus venoms collected in the States of Goias and Mato Grosso (central Brazil) is particularly interesting since this toxin has myotoxin and neurotoxin activities and accounts for $20 \%$ of the dry venom neight. These findings suggested that the crotoxin isoforms from Crotalus durissus collilineatus probably plays an important role in this venom's action (Ponce-Soto, 2002). Several studies have shown that the venom of Crotalus durissus terrificus contains various isoforms of $\mathrm{PLA}_{2}$ (Faure and Bon, 1987, 1988; Faure, 1991, 1993, 1994). In this work, we describe the biochemical and pharmacological characterization of a new crotoxin $\mathrm{B}$ isoform $\mathrm{PLA}_{2}$ (F6a) of crotoxin $\mathrm{B}$ from Crotalus durissus collilineatus.

\section{MATERIALS AND METHODS}

\subsection{Venom, Chemicals and Reagents}

Dessicated Crotalus durissus collilineatus venom was purchased from a private serpentarium (Batatais, SP, Brazil). All chemicals and reagents used in this work were of analytical or sequencing grade.

\subsection{Animals}

Male HY-LINE W36 chickens (4-8 days old) were kindly supplied by Granja Ito S/A (Sumaré, SP, Brazil). Animals had free access to food and water. The Animal Services Unit of the State University of Campinas (UNICAMP) supplied male Swiss white mice $(26-32 \mathrm{~g})$. The mice were housed at $25{ }^{\circ} \mathrm{C}$ on a $12 \mathrm{~h} \mathrm{light/dark} \mathrm{cycle} \mathrm{and} \mathrm{had} \mathrm{free} \mathrm{ac-}$ cess to food and water.

\subsection{Isolation and Purification of New PLA $\mathrm{A}_{2}$ Isoform F6a in Reverse Phase HPLC (RP-HPLC)}

Twenty milligrams of the whole venom of $\mathrm{CrO}$ talus durissus collilineatus were dissolved in $250 \mu 1$ of $0.1 \%(\mathrm{v} / \mathrm{v})$ trifluoroacetic acid (solvent A) and the resulting solution was clarified by centrifugation prior to loading the supernatant onto a $\mu$-Bondapack C-18 column $(0.78 \mathrm{~cm} \times 30 \mathrm{~cm}$; Waters 991 PDA system). Proteins were eluted with a linear gradient $(0-100 \%)$ of $66.5 \%(\mathrm{v} / \mathrm{v})$ acetonitrile in $0.1 \%(\mathrm{v} / \mathrm{v})$ trifluoroacetic acid (solvent $\mathrm{B}$ ), at a flow rate of $2.0 \mathrm{ml} / \mathrm{min}$. The elution profile was monitored at $280 \mathrm{~nm}$ and fractions were manually collected, lyophilized and stored at $-20^{\circ} \mathrm{C}$. The purified proteins obtained were referred as $\mathrm{F} 6$ and F6a.

\subsection{PLA 2 Activity.}

$\mathrm{PLA}_{2}$ activity was measured using the assay described (Cho and Kézdy, 1991) and (Holzer and Mackessy, 1996), modified for 96-well plates (PonceSoto, 2002). The standard assay mixture contained $200 \mu \mathrm{l}$ of buffer $(10 \mathrm{mM}$ Tris- $\mathrm{HCl}, 10 \mathrm{mM} \mathrm{CaCl}$, $100 \mathrm{mM} \mathrm{NaCl}, \mathrm{pH} 8.0$ ), $20 \mu \mathrm{l}$ of substrate (4-nitro3-octanoyloxy-benzoic acid), $20 \mu \mathrm{l}$ of water and $20 \mu \mathrm{l}$ of $\mathrm{PLA}_{2}$ in a final volume of $260 \mu \mathrm{l}$. After the addition of $\mathrm{PLA}_{2}(20 \mu \mathrm{g})$, the mixture was incubated for up to $40 \mathrm{~min}$ at $37^{\circ} \mathrm{C}$, with the absorbance 
being read at $10 \mathrm{~min}$ intervals. The enzyme activity, expressed as the initial velocity of the reaction (Vo) was calculated based on the increase in absorbance after $20 \mathrm{~min}$. The inhibition of $\mathrm{PLA}_{2}$ activity by crotapotin was determined by co-incubating both proteins for $30 \mathrm{~min}$ at $37^{\circ} \mathrm{C}$ and then assaying the residual enzyme activity. All assays were conducted in triplicate, and the absorbances at $425 \mathrm{~nm}$ were measured using a SpectraMax 340 multiwell plate reader (Molecular Devices).

\subsection{Amino Acid Analysis}

Amino acid analysis was performed on a PicoTag amino acid analyzer (Water System) as described elsewhere (Henrikson and Meredith, 1984). One nanomole of $\mathrm{PLA}_{2}$ or isoforms of crotapotins was hydrolyzed in $6 \mathrm{M} \mathrm{HCL} / 1 \%$ phenol at $106^{\circ} \mathrm{C}$ for $24 \mathrm{~h}$. The hydrolysates were reacted with $20 \mu \mathrm{L}$ of fresh derivatization solution (methanol:triethylamine:water:phenylisothiocyanate, 7:1:1:1, v/v) for $1 \mathrm{~h}$ at room temperature. After pre-column derivatization, PTC amino acids were identified on a reverse phase HPLC-column by comparing their retention times to those of standard PTC-amino acids (Pierce). Cysteine residues were quantified as cysteic acid.

\subsection{Reduction and Carboxymethylation of Protein

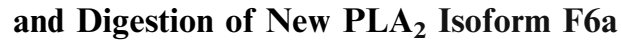

One milligram of purified $\mathrm{PLA}_{2} \mathrm{~F} 6 \mathrm{a}$ isoform was dissolved in $6 \mathrm{M}$ guanidine chloride (Merck) containing $0.4 \mathrm{M}$ Tris- $\mathrm{HCl}$ and $2 \mathrm{mM}$ EDTA $(\mathrm{pH}$ 8.1); this was reduced with DTT and then carboxymethylated with $14 \mathrm{C}$ iodoacetic acid (Ponce-Soto, 2006). Desalting was performed on a Sephadex G-25 column in $1 \mathrm{M}$ acetic acid at $25^{\circ} \mathrm{C}$, and the modified protein (RC-F6a) was lyophilized. The reduced and carboxymethylated protein was digested with Staphylococcus aureus protease SV8 for $17 \mathrm{~h}$ at $37^{\circ} \mathrm{C}$ using a 1:30 enzyme-to-substrate molar ratio; the reaction was stopped by lyophilization. The RC-F6a was also digested with Clostripain for $8 \mathrm{hr}$ at $37^{\circ} \mathrm{C}$ and then lyophilized again. The digested products of this treatment were fractionated by reverse-phase HPLC using a Waters PDA 991 system and a $\mathrm{C} 18 \mu$-Bondapack column. The elution of peptide peaks was made using a linear gradient consisting of $0-100 \%$ of acetonitrile in $0.1 \%$ trifluoroacetic acid $(\mathrm{v} / \mathrm{v})$.

\subsection{Sequencing procedure}

The sequencing of the N-terminal of new crotoxin $\mathrm{B}$ isoform $\mathrm{PLA}_{2} \mathrm{~F} 6 \mathrm{a}$, was conducted for the reduced and carboxymethylated protein, and the sequencing of peptide peaks in re-purified digest in products was performed using a Procise automatic sequencer (Applied). Peptides containing 14C-CMCys were monitored by detecting radioactivity with the use of a liquid scintillation counter (Beckman model L-250).

\subsection{Maldi-Tof Mass Spectrometric Analysis (MS)}

The molecular mass of new crotoxin $\mathrm{B}$ isoform $\mathrm{PLA}_{2} \mathrm{~F} 6 \mathrm{a}$ and isoforms of crotapotins (F3 and F4) were analyzed by MALDI-TOF mass spectrometry using a Voyager-DE PRO MALDI-TOF mass spectrometer (Applied Biosystems, Foster City, CA, USA). $1 \mu \mathrm{L}$. of sample on TFA $0.1 \%$ were mixed with $2 \mu \mathrm{L}$. of the matrix. For the crotapotin isoforms we used $\alpha$-cyano-4-hydroxycinnamic acid ( $\alpha$-Cyano, CHCA) $50 \%$ acetonitrile, $0.1 \%$ TFA v $/ \mathrm{v}$ and phospholipase $\mathrm{A}_{2}$ (F6); sinapinic acid (3,5-dimethoxy-4-hydroxycinnamic acid). The matrix was prepared with $30 \%$ acetonitrile and $0.1 \% \mathrm{v} / \mathrm{v}$ TFA and their mass analyzed under the following conditions: accelerate voltage $25 \mathrm{kV}$, the laser fixed in $2890 \mu \mathrm{J} / \mathrm{com} 2$, delay $300 \mathrm{~ns}$ and in linear analysis mode (Smolka, 2001).

\subsection{Mouse Phrenic Nerve-Diaphragm Muscle Preparation}

The phrenic nerve and diaphragm (Bulbring, 1946) were obtained from mice anesthetized with chloral hydrate $(300 \mathrm{mg} / \mathrm{kg}$, i.p.) and sacrificed by exsaguination. The diaphragm was removed and mounted under a tension of $5 \mathrm{~g}$ in a $5 \mathrm{ml}$ organ bath containing Tyrode solution ( $\left.\mathrm{pH} 7.4,37^{\circ} \mathrm{C}\right)$ of the following composition (mM): $\mathrm{NaCl} 137$, $\mathrm{KCl} 2.7, \mathrm{CaCl}_{2}$ 1.8, $\mathrm{MgCl}_{2} 0.49, \mathrm{NaH}_{2} \mathrm{PO}_{4}$ 0.42, $\mathrm{NaHCO}_{3} 11.9$ and glucose 11.1, aerated with $95 \%$ $\mathrm{O}_{2} \quad$ and $5 \% \quad \mathrm{CO}_{2}$. Supramaximal stimuli (4 $\times$ threshold, $0.1 \mathrm{~Hz}, 0.2 \mathrm{~ms})$ delivered from a Grass S48 stimulator (Astro-Med, Inc., W. Warwick, RI) were applied to the nerve through bipolar electrodes. Isometric muscle tension was recorded by a force displacement transducer (Load Cell BG-10 GM, Kulite Semiconductor Products, 
Inc., NJ) coupled to a physiograph (Gould, Model RS 3400) via a Gould universal amplifier (both from Gould, Inc., Recording Systems Division, Cleveland, $\mathrm{OH}$ ).

The preparations were allowed to stabilize for at least $10 \mathrm{~min}$ before the addition of crotoxin and new crotoxin $\mathrm{B}$ isoform $\mathrm{PLA}_{2} \mathrm{~F} 6 \mathrm{a}$ from Crotalus durissus collilineatus venom $(10 \mu \mathrm{g} / \mathrm{ml})$.

\subsection{Effects on the Chick Biventer Cervicis Preparation}

The biventer cervicis was removed as previously described by (Ginsborg and Warriner, 1960) and mounted under a tension of $1 \mathrm{~g}$ in a $5 \mathrm{ml}$ organ bath containing Krebs solution $(\mathrm{pH}$ 7.5, $37^{\circ} \mathrm{C}$ ) of the following composition $(\mathrm{mM}): \mathrm{NaCl}$, 118,$6 ; \mathrm{KCl}, 4.69 ; \mathrm{CaCl}_{2}, \quad 1.88 ; \quad \mathrm{KH}_{2} \mathrm{PO}_{4}, 1.17$; $\mathrm{MgSO}_{4}, 1.17 ; \mathrm{NaHCO}_{3}, 25.0 ; \mathrm{C}_{6} \mathrm{H}_{12} \mathrm{O}_{6}$ 11.65. The solution was bubbled with oxygen containing $5 \%$ $\mathrm{CO}_{2}$. Stimuli $(0.1 \mathrm{~Hz}, 0.2 \mathrm{~ms}$, supramaximal stimuli, $4 \times$ threshold) from a Grass S4 stimulator were delivered to the tendon through bipolar electrodes. Thresholding muscle tension was recorded isometrically by a force-displacementtransducer (BG 25 GM Kulite) coupled to a Gould RS 3400 recorder. The preparation was allowed to stabilize for at least $15 \mathrm{~min}$ before the addition of a single dose of venom or isolated crotoxin. Contractures to exogenously applied submaximal concentrations of acetylcholine (14.6 mM for $60 \mathrm{~s})$ and $\mathrm{KCl}$ $(13.3 \mathrm{mM}$ for $120-130 \mathrm{~s})$ were obtained in the absence of nerve stimulation prior to and after the addition of the venom, as an assay for neurotoxic activity (Harvey, 1994).

\subsection{Cytotoxic Activity}

Cytotoxic activity was assayed on murine skeletal muscle $\mathrm{C} 2 \mathrm{C} 12$ myoblasts and myotubes (ATCC CRL-1772) as described (Lomonte, 1999). Variable amounts of toxin were diluted in assay medium (Dulbecco's Modified Eagle's Medium supplemented with $1 \%$ fetal calf serum) and added to cells in 96-well plates, in $150 \mu \mathrm{l}$. Controls for 0 and $100 \%$ toxicity consisted of assay medium, and $0.1 \%$ Triton X-100, respectively. After $3 \mathrm{~h}$ at $37^{\circ} \mathrm{C}$, a supernatant aliquot was collected for determination of lactic dehydrogenase (LDH; EC 1.1.1.27) activity released from damaged cells, using a kinetic assay (Wiener LDH-P UV). Experiments were carried out in triplicate.

\subsection{Statistical Analysis}

The results are reported as the means \pm SEM of $n$ experiments, as appropriate. The significance of differences between means was assessed by analysis of variance followed by Dunnett's test when several experimental groups were compared with the control group. The confidence limit for significance was $5 \%$.

\section{RESULTS}

\subsection{Purification of New Crotoxin $B$ Isoform PLA F6a}

Fractionation of Crotalus durissus collilineatus venom by reverse-phase HPLC (Fig. 1a) showed the elution of eight main fractions: F2, F3 and F4 were identified as crotapotins isoforms, F6 and F6a exhibited $\mathrm{PLA}_{2}$ activity and F101 were identified as protease, Cvx identified convulxin and $\mathrm{Gyr}$ as gyroxin, respectively.

\subsection{Activity Measurements of New Crotoxin B Isoform PLA2 F6a}

The PLA $_{2}$ activity of new crotoxin $\mathrm{B}$ isoform $\mathrm{PLA}_{2} \mathrm{~F} 6 \mathrm{a}$, were studied using the synthetic chromogenic substrate 4-nitro-3-(octanoyloxy) benzoic acid.

The $\mathrm{PLA}_{2}$ activity of whole venom from Crotalus durissus collilineatus was $1.423 \pm 0.08 \mathrm{nmol} / \mathrm{min}$, crotoxin was $2.01 \pm 0.10 \mathrm{nmol} / \mathrm{min}$, crotoxin B (F6) $9.87 \pm 0.31 \mathrm{nmol} / \mathrm{min}$ and new crotoxin $\mathrm{B}$ isoform $\mathrm{PLA}_{2}$ F6a, was $9.78 \pm 0.265 \mathrm{nmol} / \mathrm{min}$ (Fig. 1b).

The crotapotins isoforms $\mathrm{F} 3$ and $\mathrm{F} 4$ inhibited crotoxin $\mathrm{B}(\mathrm{F} 6)$ and new crotoxin $\mathrm{B}$ isoform $\mathrm{PLA}_{2}$ (F6a), activity. The crotoxin B (F6) was the least sensitive to inhibition by the crotapotin isoforms isolated here (Fig. 1b).

\subsection{Amino Acid Analysis}

The amino acid composition of new crotoxin B isoform $\mathrm{PLA}_{2}$ F6a showed a high content of basic amino acids (Arg, Lys) and hydrophobic amino acid residues (Gly, Ala). The presence of 14 halfcysteines residues suggests the presence of seven 

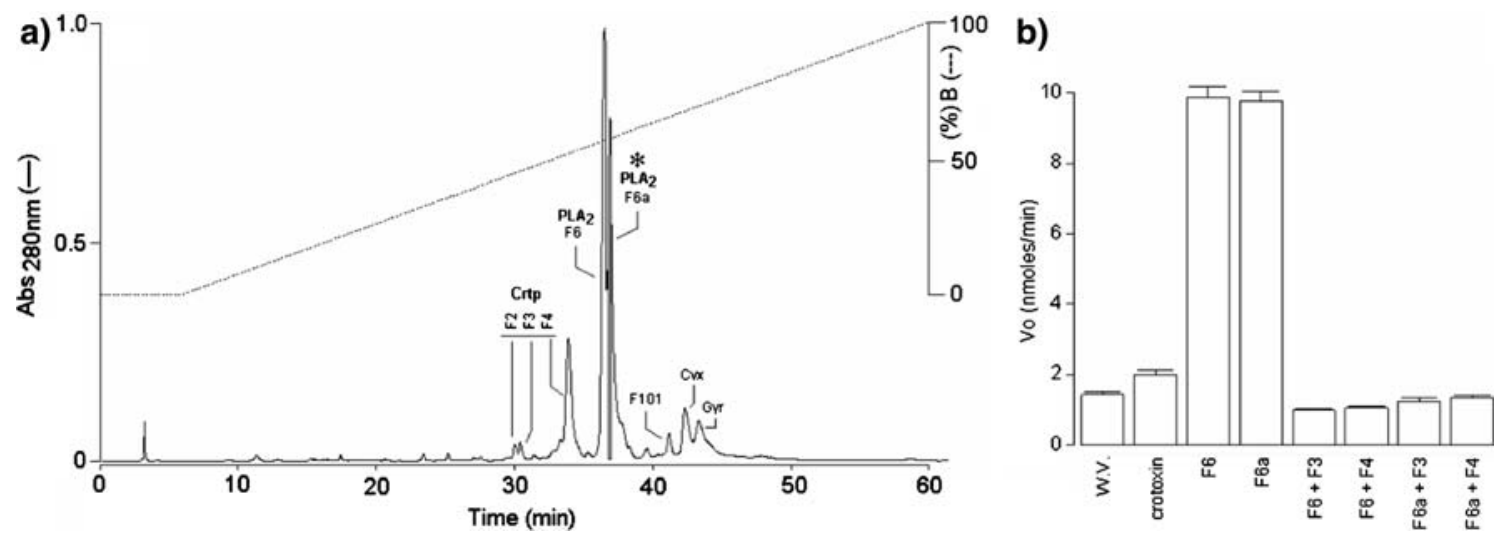

Fig. 1. (a) Elution profile of Crotalus durissus collilineatus venom showing purification of new crotoxin B isoform PLA $\mathrm{A}_{2}$ 6a in a single step, using a $\mu$-Bondapack $\mathrm{C} 18$ column. (b) Activity of $\mathrm{PLA}_{2 \mathrm{~s}}$ isolated from venoms of Crotalus durissus collilineatus (isoforms F6 and F6a) venom. Buth isoform $\mathrm{PLA}_{2}$ (F6 and F6a) was incubated with crotapotins isoforms $\mathrm{F} 3$ and $\mathrm{F} 4$ for 30 min at $37^{\circ} \mathrm{C}$, and the residual $\mathrm{PLA}_{2}$ activity was then determined.

disulfide bridges. The crotapotins F3 and F4 showed a high content of acid amino acids (Asx, Glx) and differed in their content of Ala and Pro, with F3 being slightly less hydrophobic than isoform F4 (Fig. 2a).

\subsection{Maldi-Tof Mass Spectrometric Analysis}

The MS spectral profiles of the crotoxin obtained by reverse-phase HPLC and phospholipase $\mathrm{A}_{2}$ new crotoxin $\mathrm{B}$ isoform $\mathrm{F} 6 \mathrm{a}$, and the isoforms of crotapotins (F3, F4) obtained by HPLC-FR are shown in Fig. 2b. The MS spectral data for isoforms of crotapotins F3, F4 were 8693.25 and 9341.56 Da, respectively. The $\mathrm{PLA}_{2}$ (F6) was 14 943.18 Da and whole crotoxin presented two masses of $23643.36 \mathrm{Da}$ and $24284.74 \mathrm{Da}$, due to the presence of two different crotapotin isoforms.

\subsection{Amino Acid Sequence Determination}

The new crotoxin $\mathrm{B}$ isoform $\mathrm{PLA}_{2}$ F6a subunit was reduced and carboxymethylated. It was then subjected to analytical reverse-phase HPLC, and the a)

\begin{tabular}{|c|c|c|c|c|c|c|}
\hline \begin{tabular}{|l||} 
Amino \\
scid
\end{tabular} & $F G a$ & $\begin{array}{l}\text { Nholar } \\
\text { ratio }\end{array}$ & \begin{tabular}{c|} 
Crtp \\
$(F 3)$
\end{tabular} & $\begin{array}{l}\text { Molar } \\
\text { ratio }\end{array}$ & $\begin{array}{c}\text { crtp } \\
\text { (F4) }\end{array}$ & $\begin{array}{l}\text { Molar } \\
\text { ratio }\end{array}$ \\
\hline Asx & 8 & 920,8 & 8 & 920.88 & 12 & 1381.32 \\
\hline Glx & 8 & 1032,8 & 13 & 1678.69 & 17 & 2195.21 \\
\hline Ser & 3 & 261,3 & 5 & 435.45 & 5 & 435.45 \\
\hline Gy & 14 & 798,98 & 12 & 684.84 & 10 & 570.7 \\
\hline His & 3 & 411,48 & 1 & 137.16 & 1 & 137.16 \\
\hline Arg & 12 & 1874,52 & 2 & 312.42 & 2 & 312.42 \\
\hline Thr & 8 & ৪৪8,96 & 5 & 555.6 & 5 & 555.6 \\
\hline Ala & 10 & 710,9 & 7 & 497.63 & 5 & 355.45 \\
\hline Pro & 7 & 679,91 & 10 & 971.3 & 6 & 582.78 \\
\hline Tyr & 12 & 1369,8 & 3 & 342.45 & 4 & 456.6 \\
\hline Val & 4 & 652,6 & 1 & 163.15 & 1 & 163.15 \\
\hline Met & 2 & 262,4 & 1 & 131.21 & 1 & 131.21 \\
\hline Cys & 14 & 1443,4 & 8 & 825.12 & 9 & 928.26 \\
\hline lle & 5 & 515,85 & 2 & 20634 & 3 & 309.51 \\
\hline Len & 6 & 679,02 & 1 & 113.17 & 1 & 113.17 \\
\hline Phe & 7 & 1030,33 & 3 & 441.57 & 3 & 441,57 \\
\hline Lys & 11 & 1410,09 & 2 & 256.38 & 2 & 256.38 \\
\hline$T p$ & $\mathrm{ND}^{*}$ & - & $\mathrm{ND}^{*}$ & - & $\mathrm{ND}^{*}$ & - \\
\hline Total & 134 & 14943.14 & 84 & |8691.36|| & 87 & 9343.94 \\
\hline
\end{tabular}

b)

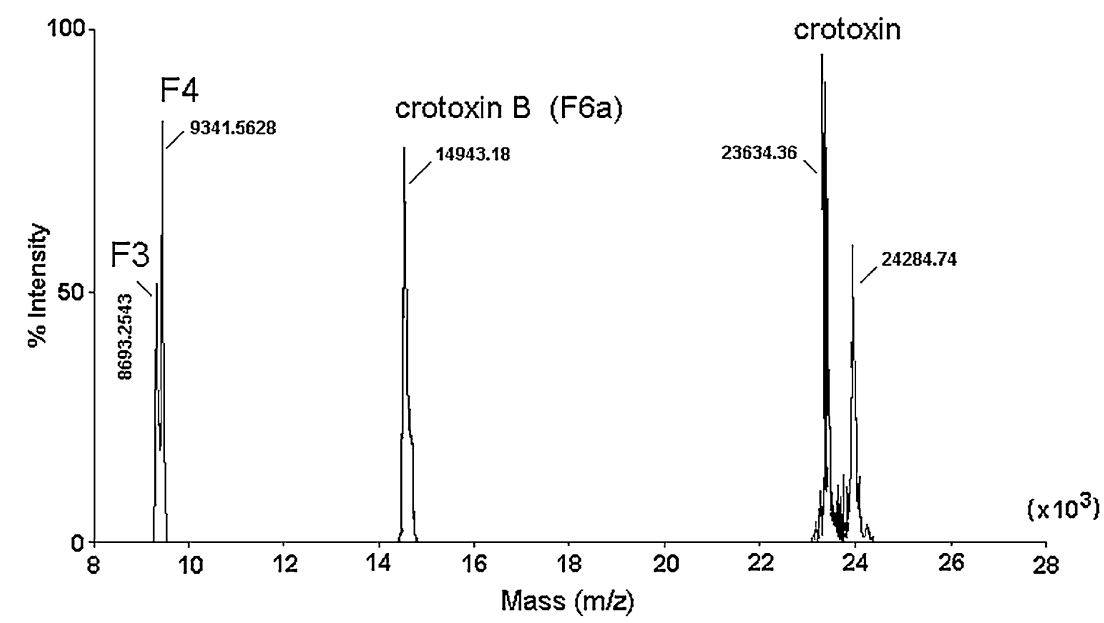

Fig. 2. (a) Amino acid composition of new crotoxin B isoform PLA 2 F6a and isoforms of crotapotin (F3 and F4) of the complex crotoxin. (b) Determination mass from crotapotin isoforms F3, F4, to new crotoxin B isoform PLA $\mathrm{F}_{2}$ 6a and crotoxin by Mass Spectrometry MALDI-tof. 


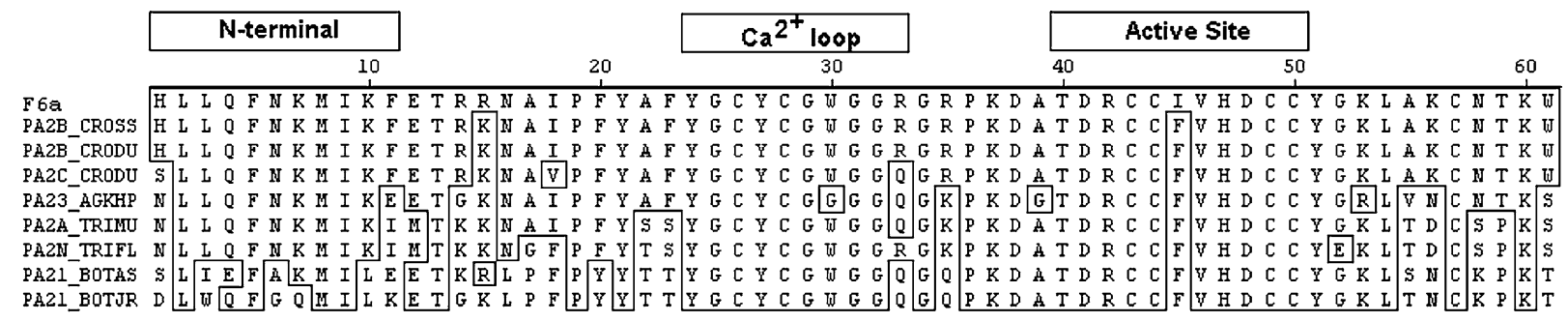

\begin{tabular}{|l|l|l|l|l|}
\hline B-Wing & \multicolumn{2}{|c|}{ Lelix 3 } & \multicolumn{2}{|c|}{ Lysine rich region } \\
70 & 90 & 100 & 110 & 120 \\
\hline
\end{tabular}

F6a DFYRY SLRSGYFQCGKGTWCEQOCIECDRYAAECLRESLSTYRYGYMIYPDSRCRGPSETC PA2B_CROSS D I T Y P Y S S L K S S G G Y I T C C G K G T W C E E D I C E C D R V A A A E C L R R R S L S T Y

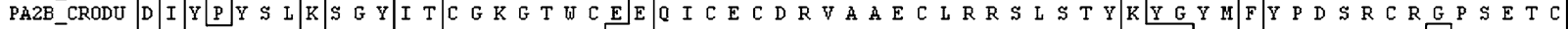
PA2C CRODU D I Y R Y S L K S G Y I T C G K G T W C K E Q I C E C D R V A A E C L R R S L S T Y K N E Y M F Y P D S R C R E P S E T C PA23_AGKHP D I I Y S T Y S S L

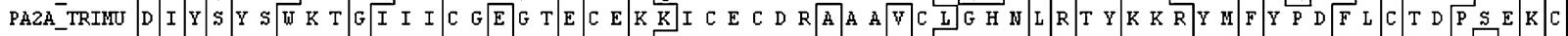
PA2N_TRIFL D

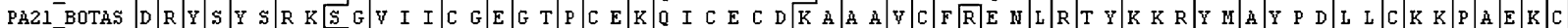

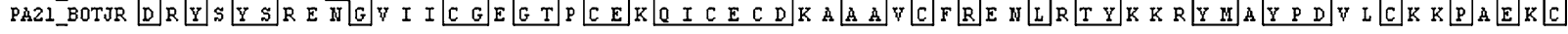

Fig. 3. Amino acid sequence and molecular homology of new crotoxin B isoform PLA 2 F6a from Crotalus durissus collilineatus with other PLA2: PA2B CROSS from Crotalus scutulatus scutulatus (Aird, S.D., et al., 1990) 91.8\%; PA2B CRODU from Crotalus durissus terrificus (Aird, S.D., et al., 1986) 91.8\%; PA2C_CRODU from Crotalus durissus terrificus (Faure, G., et al., 1994) 86.9\%; PA23_ AGKHP from Agkistrodon halys Pallas (Kondo, K., et al., 1989) 73\%; PA2A_TRIMU from Trimeresurus mucrosquamatus (Tsai, I.H., et al., 1995) 65.6\%; PA2N_TRIFL from Trimeresurus flavoviridis (Chijiwa, T., et al., 2003) 63.1\%; PA21_BOTAS from Bothrops asper (Kaiser, I.I., et al., 1990) 60.7\% and PA21_BOTJR from Bothrops jararacussu (Moura-da-Silva, A.M., et al., 1995) 59\%.

purified fraction was digested with SV8 and clostripain. Digestion with SV8 and clostripain resulted in nine and ten major peaks, respectively, in reversephase HPLC. The new crotoxin $\mathrm{B}$ isoform $\mathrm{PLA}_{2}$ F6a revealed a sequence of 122 amino acids, with approximately $90 \%$ homology with crotoxin B from Crotalus durissus terrificus and Mojave toxin, although this similarity fell to around $70 \%$ when compared with other venom PLA2s (Fig. 3). Crotoxin $\mathrm{B}$ showed high sequence identity with other snake venom $\mathrm{PLA}_{2} \mathrm{~S}$ in the $\mathrm{Ca}^{2+}$ binding loop and in the active site region (Fig. 3).

\subsection{Effects on the Mouse Phrenic Nerve-diaphragm and Chick Biventer Cervicis Preparation}

The effect on neuromuscular preparation of whole crotoxin and new crotoxin $\mathrm{B}$ isoform $\mathrm{PLA}_{2}$ F6a from Crotalus durissus collilineatus was studied in mouse phrenic nerve-diaphragm and chick biventer cervicis nerve-muscle preparations. When using a concentration of $10 \mu \mathrm{g} / \mathrm{ml}$, whole crotoxin affected the neuro-muscular transmission in both systems tested (Fig. 4), with times to reach $50 \%$ blockade of $82 \mathrm{~min} \pm 1.12 \mathrm{~min}$ for mouse phrenic nerve-diaphragm preparation and $19 \pm 0.98 \mathrm{~min}$ for chick biventer cervicis preparation. For both prepa- rations the blockade was irreversible. The crotoxin or new crotoxin $\mathrm{B}$ isoform $\mathrm{PLA}_{2}$ (F6a), did not significantly blockade the $\mathrm{ACh}$ and $\mathrm{KCl}$-induced contractures when compared to the control values (Fig. 4d). In the control preparations, the contracture to $\mathrm{ACh}$ and $\mathrm{KCl}$ kept stable, after a $120 \mathrm{~min}$ indirect stimulation when compared to the control values (data not shown).

In the case of the new crotoxin $\mathrm{B}$ isoform $\mathrm{PLA}_{2}$ F6a the results were different depending on the preparation used. Crotoxin B did not affect neuromuscular transmission in mouse phrenic nervediaphragm preparation, but induced a decrease in twicht tension in the chick biventer cervicis preparation (Fig. 4b). Again, in the latter preparation, the blockade was irreversible after washing. The average time required to reach $50 \%$ blockade was crotoxin $22.75 \pm 1.11$ and new crotoxin $\mathrm{B}$ isoform $\mathrm{PLA}_{2} \mathrm{~F} 6 \mathrm{a}$ $42.61 \pm 1.35$ min for chick biventer cervicis nervemuscle preparation (Fig. 3c). In control experiments, the registration of the contractions was stable $(92 \%$ during $120 \mathrm{~min}$ ) (Fig 4).

\subsection{Cytotoxic Effect on Myoblasts and Myotubes}

In vitro, crotoxin was devoid of cytotoxicity when tested against both $\mathrm{C} 2 \mathrm{C} 12$ myoblasts and 

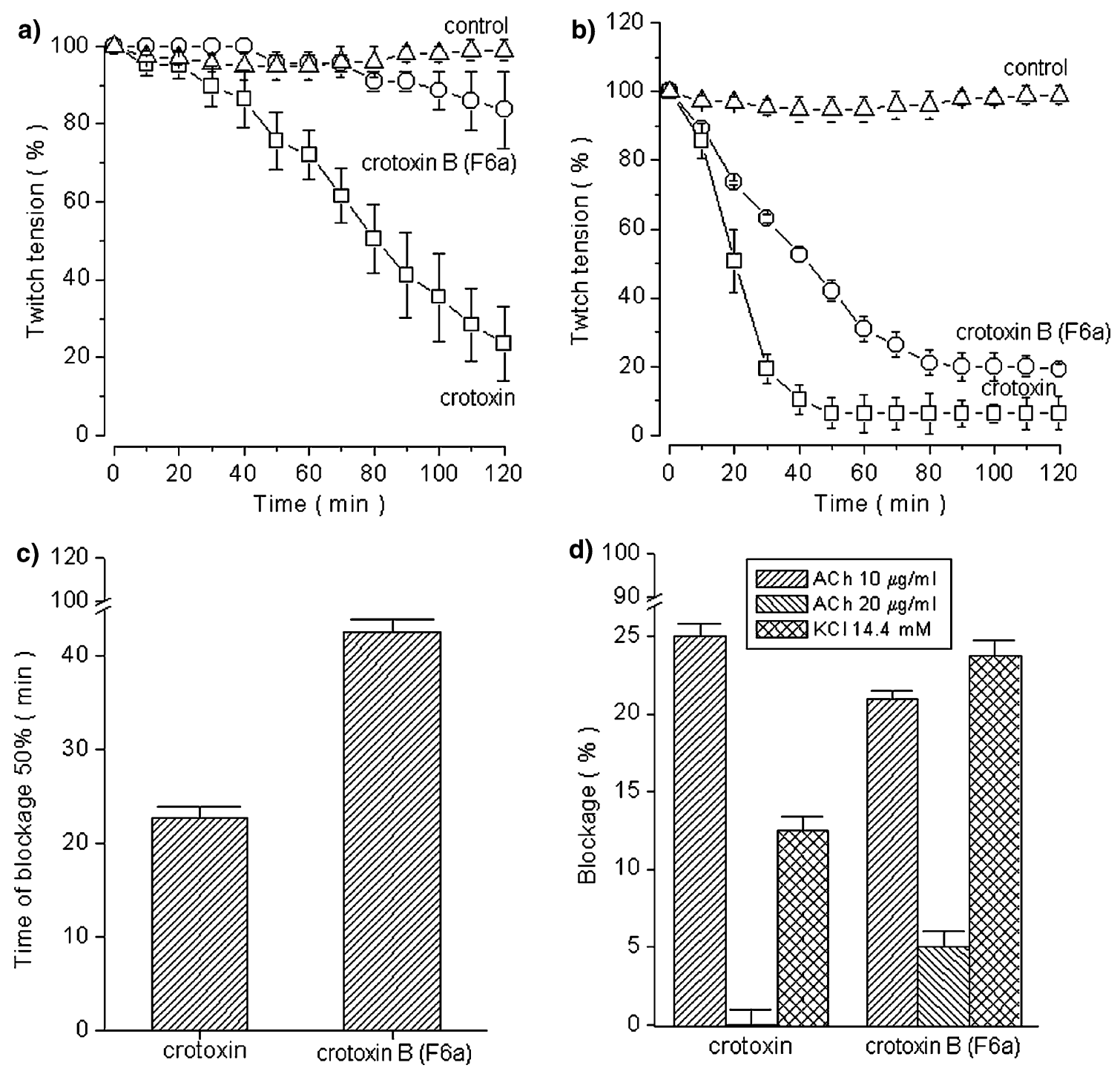

Fig. 4. (a) Neurotoxic activity of crotoxin and new crotoxin $B$ isoform $\mathrm{PLA}_{2}$ F6a in mouse phrenic nerve-diaphragm preparations, which were allowed to stabilize for at least $20 \mathrm{~min}$ before the addition of a single dose $(10 \mu \mathrm{g} / \mathrm{ml})$ of each of the toxins followed by incubation for $120 \mathrm{~min}(n=5)$. (b) Neurotoxic activity of crotoxin and new crotoxin B isoform PLA 2 F6a in the chick biventer cervicis preparation, which were allowed to stabilize for at least $20 \mathrm{~min}$ before the addition of a single dose $(10 \mu \mathrm{g} / \mathrm{ml})$ of each of the crotoxin or new crotoxin $\mathrm{B}$ isoform $\mathrm{PLA}_{2} \mathrm{~F} 6 \mathrm{a}$. (c) Effect of blockage $50 \%$ of the crotoxin and new crotoxin B isoform PLA $\mathrm{F}_{2}$ a from Crotalus durissus collilineatus on muscle contractions induced and (d) Effect of the crotoxin and new crotoxin B isoform PLA 2 F6a from Crotalus durissus collilineatus on the response of the chick biventer cervicis preparation to the acetylcholine (Ach 10 and $20 \mu \mathrm{g} / \mathrm{ml}$ ) and potassium (KCl $13.4 \mathrm{mM}$ )

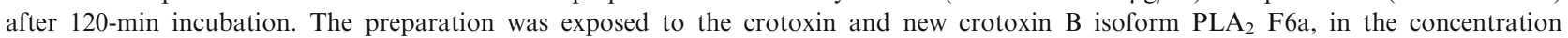
$10 \mathrm{mg} / \mathrm{ml}$ placed under each histogram. Each point represents the average of five experiments EPM per concentration $p<0.05$ compared to the corresponding control (Krebs solution alone) (Student $t$-test).

myotubes, at doses up to $40 \mu \mathrm{g} / \mathrm{well}(265 \mu \mathrm{g} / \mathrm{ml})$. At this dose, new crotoxin B isoform PLA 2 (F6a) was able to lyse both types of cells, with a higher cytotoxic effect towards myotubes than towards less differentiated myoblasts (Fig. 5).

\section{DISCUSSION}

The purification protocols used here were simple, quick, efficient, and reproducible, yielding pure crotapotin isoforms F3 and F4 and crotoxin B 


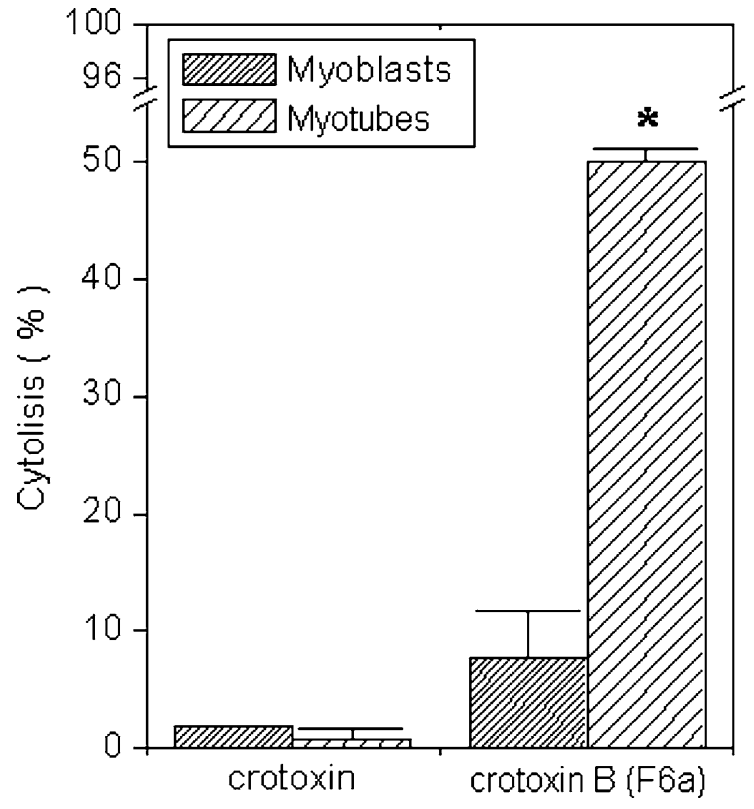

Fig. 5 In vitro membrane-damaging activities of Crotalus durissus collilineatus crotoxin and new crotoxin $\mathrm{B}$ isoform $\mathrm{PLA}_{2}$ F6a. Cytotoxic activity on murine $\mathrm{C} 2 \mathrm{C} 12$ skeletal muscle myoblasts and myotubes. Cell lysis was estimated by the release of lactic dehydrogenase $(\mathrm{LDH})$ to supernatants, after $3 \mathrm{~h}$ of exposure to the toxin, in a volume of $150 \mu \mathrm{l} /$ well. Each point represents the mean $\pm \mathrm{SD}$ of triplicate cell cultures.

$\mathrm{PLA}_{2}$ isoforms F6 and F6a from the venom of Crotalus durissus collilineatus. Thus, although crotapotins isoforms $\mathrm{F} 3$ and $\mathrm{F} 4$ had similar chemical properties, the two proteins different in their ability to inhibit of isoforms of $\mathrm{PLA}_{2}$ (F6 and F6a). This finding suggests that these two crotapotins differ in their structure and that this difference is reflected in their inhibitory activity. These conclusions agree with work by (Faure and Bon, 1988) and (PonceSoto, 2002).

The crotoxin has been described as the most potent neurotoxic compound found to Crotalus durissus terrificus venom and this compound it is composed by reversible association between a little neurotoxic basic $\mathrm{PLA}_{2}$ and non neurotoxic and acid compound (crotapotin) (Habermann and Breithaupt, 1978; Faure and Bon, 1988). Thus during years the neurotoxic effect of crotalic $\mathrm{PLA}_{2}$ is mainly dependent of the presence of crotapotin. But in this paper we showed that Crotalus durissus collilineatus new crotoxin $\mathrm{B}$ isoform $\mathrm{PLA}_{2}(\mathrm{~F} 6 \mathrm{a})$ induced a strong neurotoxic and cytotoxic effect independently the presence of crotapotin and this effect is strongly dependent of basic amino acid residue located in the new crotoxin $\mathrm{B}$ isoform $\mathrm{PLA}_{2}$ F6a.

As expected, of new crotoxin $\mathrm{B}$ isoform $\mathrm{PLA}_{2}$ F6a from Crotalus durissus collilineatus shows high sequence identity with crotoxin B from Crotalus durissus terrificus and with the $\mathrm{PLA}_{2}$ subunit of Mojave toxin, from the North American rattlesnake Crotalus scutulatus. Moreover, two different crotapotin variants were isolated. Heterogeneity in the composition of crotapotins present in crotoxin explains the existence of multiple crotoxin isoforms in the venom of Crotalus durissus terrificus (Faure and Bon, 1987). It is therefore likely that a similar phenomenon occurs in Crotalus durissus collilineatus.

The amino acid sequence of the new crotoxin B isoform $\mathrm{PLA}_{2}$ F6a showed highly conserved basic amino acid residues in the C-terminal domain, which, according to some authors, is responsible for heparin binding and membrane-destabilizing effect (Lomonte, 1994; Selistre de Araújo, 1996; Chioato, 2002). This region seems to be important in accounting for the biological action and interaction of these $\mathrm{PLA}_{2}$ with the cell membrane and the presence of basic amino acid residues play an important role for these activities (Gutiérrez and Lomonte, 1995; Lomonte, 2003).

Crotoxin from Crotalus durissus terrificus has been extensively characterized as a potent neurotoxic $\mathrm{PLA}_{2}$ complex which acts predominantly at the presynaptic level in neuromuscular junctions (Brazil and Excell, 1971; Hawgood and Smith, 1977), which contains basic phospholipase $A_{2}$ and an acidic protein, crotapotin (Rubsamen, 1971). We assessed the ability of whole crotoxin and crotoxin $B$ to affect neuro-muscular transmission in two different preparations.

When using mouse phrenic nerve-diaphragm preparation, only whole crotoxin induce blockade, whereas both crotoxin and new crotoxin $\mathrm{B}$ isoform $\mathrm{PLA}_{2}$ F6a affected chick biventer cervicis preparation. Thus, as previously demonstrated for crotoxin isolated from Crotalus durissus terrificus venom, the isolated subunit B is able to exert neurotoxic effects, although its neurotoxicity is greatly enhanced by the presence of crotapotin (Habermann and Breithaupt, 1978; Bon, 1989).

Postsynaptically active neurotoxins would block response to cholinoreceptors agonists. A presynaptically active neurotoxin would abolish nerve-evoked twitches, without affecting response to cholinoreceptor agonists. The fact that crotoxin and the new crotoxin $\mathrm{B}$ isoform $\mathrm{PLA}_{2} \mathrm{~F} 6 \mathrm{a}$ from 
Crotalus durissus collilineatus did not significantly affect the responses to $\mathrm{ACh}$ and $\mathrm{KCl}$ added in the preparation agrees with what is known about the interference of the Crotalus durissus terrificus venom on ACh release (Hawgood and Smith, 1977; Hawgood and Santana de Sá, 1979).

Crotoxin is known to induce potent myotoxicity in vivo, and the whole crotoxin complex is more active at inducing muscle damage than isolated crotoxin B (Gopalakrishnakone, 1984).

Pharmacologically, the whole crotoxin exercise both pre- and post-synaptic actions, although the crotapotin component is generally considered to be pharmacologically inactive, serving merely as a chaperon protein for the $\mathrm{PLA}_{2}$ and increasing its biological activity (Breithaupt, 1976; Habermann and Breithaupt, 1978; Bon, 1979). Although different subspecies of Crotalus durissus have been found to present slight variation in the properties of their $\mathrm{PLA}_{2}$, the crotapotins has been considered to be the same. In the subspecies investigated here, however (Crotalus durissus collilineatus) the new crotoxin B isoform $\mathrm{PLA}_{2}$ F6a showed neurotoxic in the chick biventer cervicis preparation and cytotoxic activities independent the presence of crotapotin.

The Crotalus durissus collilineatus $\mathrm{PLA}_{2}$ showed conserved basic amino acid residues similarly to found in the bothropic PLA 2 . This region probably is involved in the neurotoxic activity of this $\mathrm{PLA}_{2}$. Several studies made with other $\mathrm{PLA}_{2}$ also showed that $\mathrm{C}$-terminal region play important role for the neurotoxic effect and the difference in the amino acid sequences of this region has a evident relationship to neurotoxic potency (Krizaj, 1989; Curin-Serbec, 1991; Lomonte, 2003; Prijatelj, 2003). Thus these conserved basic amino acid residues seem to be involved in the neurotoxic effect of new crotoxin $\mathrm{B}$ isoform $\mathrm{PLA}_{2}$ F6a from the Crotalus durissus collilineatus but it is not the unique region responsible for this effect.

The new crotoxin $\mathrm{B}$ isoform $\mathrm{PLA}_{2} \mathrm{~F} 6 \mathrm{a}$ exhibits specific neurotoxic activity (as other D49 neurotoxic $\mathrm{PLA}_{2}$ ), in the presence of acid subunits as seen in the mouse phrenic nerve-diaphragm but also independent of this subunit as seen in the chick biventer cervicis preparation. In the agreement with our results, we conclude that toxicity, neurotoxicity or cytotoxicity of new crotoxin B isoform PLA $_{2}$ (F6a) is not dependent on the presence of other molecules (as crotapotin) and probably involve other mechanisms related with the specificity or bound likeness to receivers.
Our present findings on a mouse muscle cell line grown in culture evidence that whole crotoxin lacks cytotoxicity on myoblasts and on differentiated myotubes, whereas new crotoxin $\mathrm{B}$ isoform $\mathrm{PLA}_{2}$ (F6a) affects myotubes in the experimental conditions of this study. It is suggested that the myoblasts and myotubes utilized lack a specific high affinity receptor for crotoxin, thus explaining the lack of effect of whole crotoxin, since the complex probably does not dissociate in these conditions. In contrast, isolated new crotoxin $\mathrm{B}$ isoform $\mathrm{PLA}_{2}$ (F6a) is able to affect myotubes, probably by directly altering the integrity of the plasma membrane of these multinucleated cells.

These findings agree with previous studies that documented the higher toxicity of new crotoxin B isoform $\mathrm{PLA}_{2}$ (F6a), when compared with whole crotoxin, on myotubes in culture (Lomonte, 1999). These results are in agreement with recent studies demonstrating the higher susceptibility of myotubes over myoblasts to the cytolytic effect of several class II $\mathrm{PLA}_{2} \mathrm{~S}$ with myotoxic activity, but not to general cytolytic agents (Angulo and Lomonte, 2002).

\section{ACKNOWLEDGMENTS}

The authors thank Paulo A. Baldasso and Marino Forner for general technical help, Vera Lucia Bonfim for redacted help and FAPESP supported this work. We thank Dr J. M. Gutierrez to read this manuscript critically as well as for their valuable and important contributions. This work was supported by FAPESP and is part of $\mathrm{PhD}$ thesis by Luis Alberto Ponce-Soto.

\section{REFERENCES}

Angulo, Y., Olamendi-Portugal, T., Alape-Girón, A., Possani, L. D., and Lomonte, B. (2002). Int. J. Biochem. 34: 1268-1278.

Araújo, F. A. A., SantaLúcia, M., and Cabral, R. F. (2003). In: Cardoso, J. L. C., França, F. O. S., Fan, H. W., Málaque, C. M. S., and Haddad Jr., V. (eds.), Sarvier/FAPESP, São Paulo, pp 6-12.

Azevedo-Marques, M. M., Cupo, P., Coimbra, T. M., Hering, S. E., Rossi, M. A., and Laure, C. J (1982). Toxicon 23: 631636.

Beghini, D. G., Toyama, M. H., Hyslop, S., Sodek, L., Novello, J. C., and Marangoni, S. (2000). J. Protein Chem. 19: 603-607.

Bon, C., Bouchier, C., Choumet, V., Faure, G., Jiang, M. S., Lambezat, M. P., Radvanyi, F., and Saliou, B (1989). Acta Physiol. Pharmacol. Latinoam. 39: (4), 439-448.

Bon, C., Changeux, J. P., Jeng, T. W., and Fraenkel-Conrat, H. (1979). Eur. J. Biochem. 99: 471-481.

Brazil, O. V., and Excell, B. J. (1971). J Physiol. 212: (2), 34P-35P. 
Breithaupt, H. (1976) Toxicon 14: 221-233.

Bülbring, E. (1946) Br. J. Pharmacol. 1: 38-61.

Chioato, L., De Oliveira, A. H., Ruller, R., Sa, J. M., and Ward, R.J. (2002). Biochem. J. 366: (Pt 3), 971-976.

Cho, W., and Kézdy, F. J. (1991). Methods Enzymol. 197: 75-79.

Curin-Serbec, V., Novak, D., Babnik, J., Turk, D., and Gubensek, F. (1991). A. FEBS Lett. 280: (1), 175-178.

Faure, G., and Bon, C. (1987). Taxicon 25: (2), 229-234.

Faure, G., and Bon, C. (1988). Biochemistry 27: 730-738.

Faure, G., Choumet, V., Bouchier, C., Camoin, L., Guillaume, J. L., Monegier, B., Vuilhorgne, M., and Bon, C. (1994). Eur. J. Biochem. 223: 161-164.

Faure, G., Guillaume, J. L., Camoin, L., Saliou, B., and Bon, C. (1991). Biochemistry 30: 8074-8083.

Faure, G., Harvey, A. L., Thomson, E., Saliou, B., Radvanyi, F., and Bon, C. (1993). Eur. J. Biochem. 214: (2), 491-496.

Ginsborg, B. L., and Warriner, J. (1960). Brit. J. Physiol. 150: 707717.

Gopalakrishnakone, P., Dempster, D. W., Hawgood, B. J., and Elder, H. Y. (1984). Toxicon. 22: (1), 85-98.

Gutierrez, J. M., and Lomonte, B. (1995). Toxicon 33: (11), 14051424.

Gutierrez, J. M., and Ownby, C. L. (2003). Toxicon 42: (8), 915931.

Habermann, E., and Breithaupt, H. (1978). Toxicon 16: 19-30.

Harvey, A. L., Barfaraz, A., Thompson, E., Faiz, A., Preston, S., and Harris, J. B. (1994). Toxicon. 32: 257-265.

Hawgood, B. J., and de Santana Sa, S. (1979). Neuroscience 4: (2), 293-303.

Hawgood, B. J., and Smith, J. (1977). J Physiol. 266: (1), 91P-92P.

Heinrikson, R. L., and Meredith, S. C. (1984). Anal. Biochem. 13: $65-72$.
Holzer, M., and Mackessy, S. P. (1996). Toxicon 34: 1149-1155.

Kini, R. M., and Evans, H. J. (1989). Toxicon 27: (6), 613-635.

Kini, R. M. (2003) Toxicon 42: (8), 827-840.

Krizaj, I., Turk, D., Ritonja, A., and Gubensek, F. (1989). Biochim. Biophys. Acta. 30: (2), 198-202.

Lambeau, G., and Lazdunski, M. (1999). Trends Pharmacol. Sci. 20: (4), $162-170$

Lennon, B. W., and Lomonte, B., Angulo, Y., and Santamaría, C. (2003). Toxicon 42: (3), 307-312.

Lomonte, B., Pizarro-Cerda, J., Angulo, Y., Gorvel, J. P., and Moreno, E. (1999). Biochim. Biophys. Acta. 1461: (1), 19-26.

Lomonte, B., Tarkowski, A., and Hanson, L. A. (1994). Toxicon 32: (11), 1359-1369.

Oliveira, D. G., Toyama, M. H., Novello, J. C., Beriam, L. O., and Marangoni, S. (2002). J. Protein Chem. 21: (3), 161-168.

Ponce-Soto, L. A, Toyama, M. H., Hyslop, S., Novello, J. C., and Marangoni, S. (2002). J Protein Chem. 21: (3), 131-136.

Ponce-Soto, L. A., Bonfim, V. L., Rodrigues-Simioni, L., Novello, J. C., and Marangoni, S. (2006). Protein J. 25: (2), 147-155.

Prijatelj, P., Sribar, J., Ivanovski, G., Krizaj, I., Gubensek, F., and Pungercar, J. (2003). Eur. J. Biochem. 270: (14), 3018-3025.

Rangel-Santos, A., Dos-Santos, E. C., Lopes-Ferreira, M., Lima, C., Cardoso, D. F., and Motam, I. (2004). Toxicon. 43: (7), $801-810$

Rubsamen, K., Breithaupt, H., and Habermann, E. (1971). Arch. Pharmacol. 270: 274-288.

de Selistre Araujo, H. S., White, S. P., and Ownby, C. L. (1996). Arch. Biochem. Biophys. 326: (1), 21-30.

Smolka, M. B., Zhou, H., Purkayastha, S., and Aebersold, R. (2001). Anal. Biochem. 297: (1), 25-31. 